\title{
Effect of hydrochloric acid and prostaglandins on pepsinogen synthesis and secretion in canine gastric chief cell monolayer cultures
}

\author{
J DEFIZE AND RICHARD H HUNT \\ From the Intestinal Disease Research Unit, McMaster University, Hamilton, Ontario, Canada
}

Summary The actions of hydrochloric acid, natural $\mathrm{PGE}_{1}, \mathrm{PGE}_{2}$ and a synthetic commercial $\mathrm{PGE}_{1}$ preparation, Enisoprost (Searle) on pepsinogen synthesis and secretion were studied in canine chief cell monolayer cultures. Hydrochloric acid, applied directly to the apical surface of chief cells using culture plate inserts (Millipore) had no effect on secretion, nor did it affect the action of any secretagogue in the basolateral medium. All prostaglandins tested showed significant stimulation of pepsinogen secretion. Basal secretion of pepsinogen after 90 min was $9 \cdot 4(1 \cdot 3) \%$ to total initial monolayer content. At $10^{-6} \mathrm{M}, \mathrm{PGE}_{1}$ stimulated secretion was $26 \cdot 1(3 \cdot 8) \%$; PGE 27.9 (4)\% and Enisoprost $28 \cdot 8(4 \cdot 2) \%$ of initial pepsinogen content. Stimulations by all tested prostaglandins were additive with carbachol $\left(10^{-4} \mathrm{M}\right)$ and $\mathrm{CCK}\left(10^{-9} \mathrm{M}\right)$, but not with VIP $\left(10^{-6} \mathrm{M}\right), \operatorname{dbcAMP}\left(10^{-3} \mathrm{M}\right)$ or forskolin $\left(1^{-6} \mathrm{M}\right)$ responses. All three prostaglandins stimulated pepsinogen synthesis as measured by ${ }^{14} \mathrm{C}$ labelled amino acid incorporation into pepsinogen. Time course experiments were similar to those for forskolin and showed shorter time delays between stimulus and increased synthesis rate than carbachol but longer than dbcAMP. Stimulated pepsinogen secretion was inhibited by high pepsin concentrations $(>800 \mu \mathrm{g} / \mathrm{ml})$ in the medium. The inhibition abolished simultaneous carbachol induced stimulation of synthesis but prostaglandin or forskolin stimulation only after two hours. Combined with the shorter response time, as compared with carbachol, these data support our previous findings that potent stimulators of cAMP production can stimulate pepsinogen synthesis directly by stimulation of mRNA synthesis, independently from an increased secretion. The additivity of effects with carbachol or CCK and similarity with forskolin stimulated synthesis supports the suggestion that the actions of prostaglandins are mediated by cAMP.

We have previously studied modulation of pepsinogen synthesis as a response to increased secretion in monolayer cultures of canine chief cells. ${ }^{1-3}$ Our results showed that pepsinogen synthesis can be stimulated by an increased secretion but that synthesis response is faster when secretion is stimulated by potent stimulators of cAMP synthesis, such as forskolin, than by secretagogues that act presumably through cellular calcium. ${ }^{3}$ It was hypothesized that these agents, through raising

Address for correspondence: Dr J Defize. Intestinal Disease Research Unit. McMaster University. HSc, Room 3N5, 1200 Main Street West, Hamilton, Ontario L8N 3Z5, Canada.

Accepted for publication 8 November 1988.
cAMP cell content, are capable of a more direct stimulation of pepsinogen synthesis by activation of DNA transcription or cAMP dependent protein kinase, resulting in increased mRNA production. Agents using cellular calcium as mediator seem to stimulate synthesis indirectly through a feed back mechanism triggered by an increased secretion. Because this increase in cAMP is concomitant with an increased secretion, however, it is difficult to differentiate between the two processes.

In this study we have therefore investigated the possibility of uncoupling secretion and synthesis by establishing a selective feed back inhibition on secretion by high concentrations of pepsin in the culture 
medium. We have further investigated the effects of hydrochloric acid and prostaglandins on pepsinogen synthesis and secretion. These studies necessitate separation of basolateral and luminal solutions of the chief cell cultures, and this was achieved by culture of cells on culture plate inserts (Millipore). This enabled the assessment of the effect of acid and pepsin on the apical membranes of the chief cell directly.

The so called cytoprotective property of prostaglandins, produced by the gastric mucosa ${ }^{4-6}$ seems to be partly caused by an inhibition of basal and stimulated acid secretion. This inhibition has been observed in a number of in vivo ${ }^{78}$ and in vitro studies. ${ }^{9}$ The prostaglandins seem to block the stimulatory action of histamine of cAMP synthesis, thereby removing the major pathway for the excitation of parietal cells by histamine or other secretagogues such as gastrin. ${ }^{9}$ The reduced acid secretion could supposedly influence pepsinogen secretion. In contrast ${ }^{10}$ prostaglandins have been found to stimulate cAMP synthesis in a non-parietal cell population of the gastric mucosa.

In vivo studies concerning the effects of prostaglandins on pepsin secretion have reported a decrease in gastric secretion volume, usually with constant remaining pepsin concentration, ${ }^{11}{ }^{12}$ indicating a reduction in total pepsin output. Recently, however, an in vitro study, using isolated gastric glands from guinea pig stomach reported an increase of pepsinogen secretion by prostaglandins. ${ }^{13}$ Moreover, this study indicated that the actions of the prostaglandins were mediated by cAMP, as the authors found potentiation of actions only between prostaglandin and those secretagogues whose actions are believed to be mediated by changes in cellular calcium.

The results from our study indicate that prostaglandin induced changes in acid output are not responsible for changes in pepsin output.

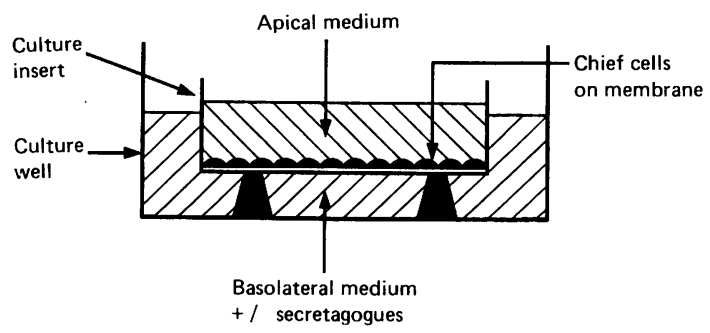

Fig. 1 Schematic representation of the Millicell culture insert technique. The chief cell monolayer is formed on the insert membrane and separates apical and basolateral solutions. Secretagogues are added to the basolateral medium.
Methods

A N I M A LS

Canine gastric chief cells were isolated as described earlier with minor modifications. ${ }^{314}$ Dogs were killed under anaesthesia using sodium pentothal $(100 \mathrm{mg} /$ $\mathrm{kg}$ ). Gastric glands were first isolated by a modification of the technique by Berglindh et al. ${ }^{15}$ is Gastric mucosa from the fundic part of the stomach was digested by collagenase (Sigma type IA) and incubated in oxygenated incubation solution at $37^{\circ} \mathrm{C}$ for 45 minutes. Free glands were collected by centrifugation at $50 \mathrm{~g}$ and further digested $(15 \mathrm{~min})$ into free cells by pronase $(1 \mathrm{mg} / \mathrm{ml})$ in calcium free medium to which was added 2 mM EDTA. Parietal and chief cells were separated on Percoll gradient centrifugation. ${ }^{31417}$ The top of the gradient, containing parietal cells was discarded, the pellet at the bottom, containing the chief cells was taken out by syringe, washed with Dulbeco's medium $(3 \times)$, and finally resuspended in Dulbeco's medium, supplemented with $10 \%$ fetal calf serum. Cells were cultured at $37^{\circ} \mathrm{C}$ and $5 \%$ $\mathrm{CO}_{2} / 95 \% \mathrm{O}_{2} \cdot{ }^{3}$ Cells $(0.5 \mathrm{ml}$, containing approximately $10^{6}$ cells) were cultured in 24 well plates (Nunc) on Millipore HA culture plate inserts (Millicell HA; $12 \mathrm{~mm}$ ). Monolayers were formed after approximately 48 hours. Peptic cells were identified by immunohistological staining, using antihuman pepsinogen antibodies. ${ }^{18}$ Viabilty of cells was tested by trypan blue exclusion.

\section{DE NOVO SYNTHESIS OF PEPSINOGEN}

Pepsinogen synthesis and secretion of this newly synthesised pepsinogen was studied by culturing chief cell monolayers in ${ }^{14} \mathrm{C}$ labelled amino acid supplemented medium. ${ }^{316}{ }^{19}$ Reagents were added to the serosal medium in the well and cells were cultured for additional time intervals to a maximum of four hours. At different time intervals, $100 \mu$ l aliquots were taken by pipette from the luminal medium in the inserts of duplicate wells to determine secreted labelled pepsinogen. The insert was taken out of the medium, cells were detached from the insert membrane by trypsinisation for three minutes at $37^{\circ} \mathrm{C}$ (trypsin/EDTA no 670-5040, Gibco) and lysed by sonification in $0.5 \mathrm{ml} 0.1 \mathrm{M}$ phosphate buffer, $\mathrm{pH} 8$. Pepsinogen was purified from cell lysates or medium by polyacrylamide gel electrophoresis (PAGE) of cell lysates and medium ( $50 \mu \mathrm{l}$ aliquots). Gels were stained for proteolytic activity to identify the pepsinogen bands in the gel or developed for fluorographic detection of ${ }^{14} \mathrm{C}$ labelled proteins. ${ }^{316} 19$ Quantitative determination of labelled pepsinogen in cells and medium was done as previously described. ${ }^{319}{ }^{14} \mathrm{C}$ incorporation specifically in pepsinogen was determined by cutting the pepsinogen pattern 


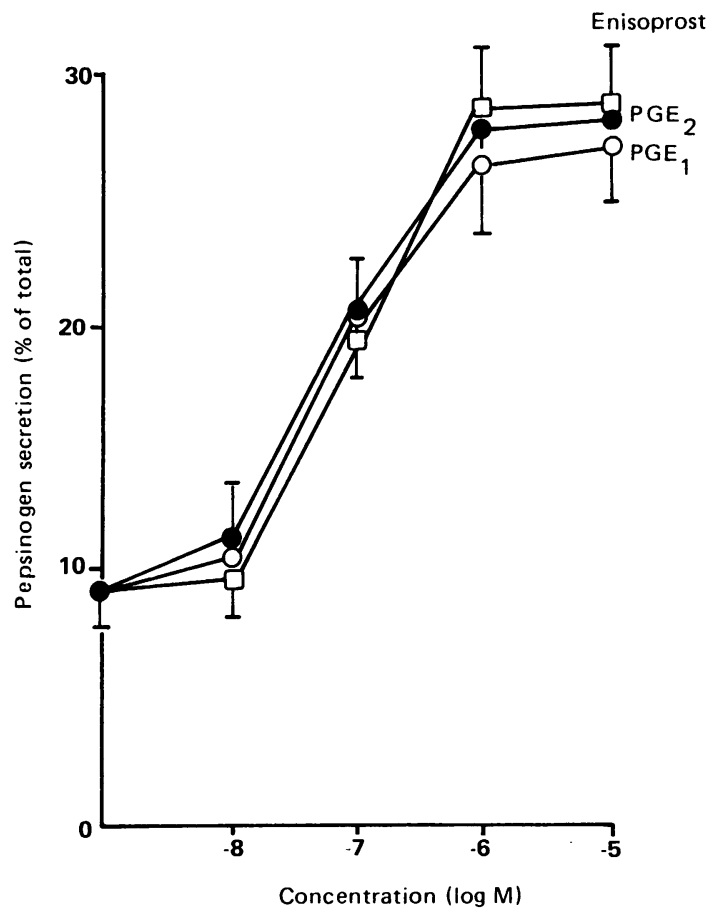

Fig. 2 Dose response curves of $P G E_{1}, P G E_{2}$, and Enisoprost on pepsinogen secretion. Pepsinogen secretion was determined after 90 min incubation and expressed as \% of initial pepsinogen content. Concentration is expressed as $\log M$. Data shown are means (SD) from four experiments, using four different cell preparations.

(identified by the specific pepsinogen activity staining after electrophoresis) out of the dried gel. ${ }^{14} \mathrm{C}$ incorporation in pepsinogen was subsequently counted by liquid scintillation. Total protein content of cells was determined by the BIORAD protein assay ${ }^{20}$ as a parameter for the number of cells at zero time. Because of the little variance found in the protein content of 24 monolayers from one cell preparation $(52(6 \cdot 2) \mu \mathrm{g})$, this was only determined in four untreated monolayers from each preparation. To correct for variations in cell number, total synthesis of pepsinogen (intracellular and secreted) was expressed as $\mathrm{CPM} / \mathrm{mg}$ total monolayer protein content, secretion of labelled pepsinogen as CPM in secreted pepsinogen $/ \mathrm{mg}$ total monolayer protein content.

\section{MEASUREMENT OF STORED PEPSINOGEN}

RELEASE

To measure release of stored pepsinogen release only, reagents were added to the serosal medium in the culture plate well, the insert medium was replaced by Krebs solution and cells were cultured for an additional 30-90 minutes. The insert medium was then assayed for peptic activity, using the human haemoglobin digestion method. ${ }^{21}$ Crystalline porcine pepsinogen (Sigma) was used as standard. Appropriate blanks were used in all assays. Stored pepsinogen secretion was expressed as percentage of initial pepsinogen content of the monolayer or as percentage of basal secretion. As for total protein content, initial total pepsinogen content was determined in four untreated monolayers from each cell preparation.

Carbachol, dbcAMP, TPA, forskolin, VIP, CCK-8, $\mathrm{PGE}_{1}$, and $\mathrm{PGE}_{2}$ were obtained from SIGMA (St Louis, USA). Enisoprost was a gift from Searle.

STATISTICAL ANALYSIS

Statistical significance of differences was evaluated with Student's $t$ test, using the mean of duplicate values and with $n$ equal to the number of stomachs from which monolayer preparations were derived.

\section{Results}

As Sanders $e t a l^{22}$ have already reported, chief cells regain their polarity during formation of monolayers, resulting in an exposure of their apical surfaces to the medium above.

As the Millicell inserts are not translucent, confluency of monolayers was tested by neutral red staining of two inserts of every 24 wells plate. Complete confluency over the whole surface is, however, only a prerequisite for measuring the influence of $\mathrm{HCl}$ specifically on the apical membranes of the cells. In these experiments, the $\mathrm{pH}$ of the basolateral medium in the well was determined for each well after incubation. Figure 1 shows a cross section of a Millicell culture insert in the culture well.

\section{MONOLAYERS ON MILLICELL CULTURE PLATE} INSERTS

Combined neutral red/trypan blue staining of cell cultures on Millipore inserts showed tight confluent monolayers over the whole membrane surface with an occasional blue stained non viable cell.

Pepsinogen secretion in monolayers grown on culture plate inserts was studied by replacing the culture medium by a Krebs solution only in the insert itself. The properties of the insert membranes are such as to allow easy access to receptors on the serosal cell membranes. This technique has the advantage that during incubation, nutrition is still available to the cell. Pepsinogen synthesis was studied using labelled medium in the well only. We did not detect measurable amounts of pepsinogen in the basolateral medium. 


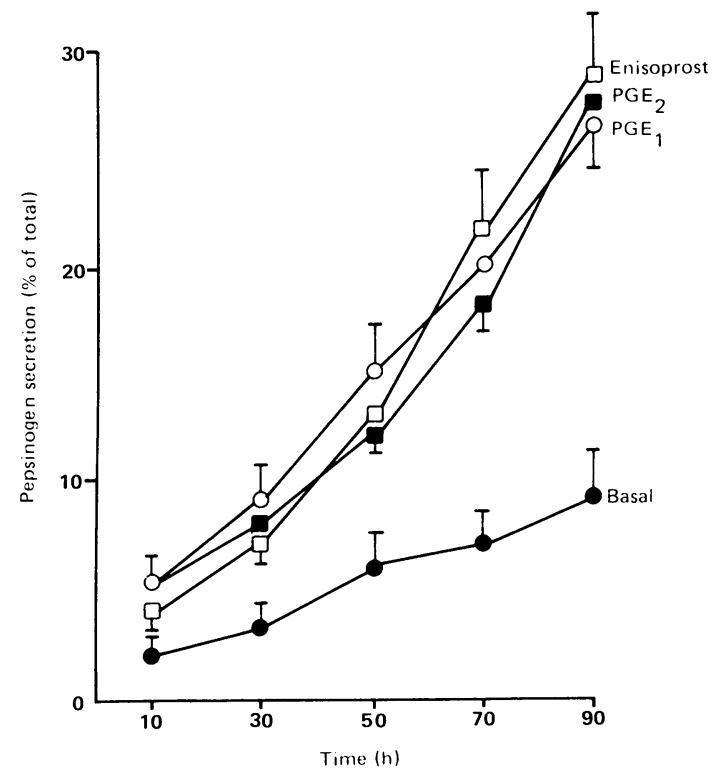

Fig. 3 Time course of pepsinogen secretion, basal and stimulated by $10^{\circ} M P G E_{1}, P G E_{2}$, or Enisoprost. Secretion is expressed as $\%$ of initial pepsinogen content and curves shown are derived from five experiments, using five different cell preparations (mean $(S D)$ ).

\section{STORED PEPSINOGEN SECRETION}

Basal secretion after 90 minutes of stored pepsinogen was $9.4(1.3) \%$ of initial pepsinogen content. Prostaglandin stimulated secretion was almost three-fold compared with basal. In Figure 2 the prostaglandin dose response curves are shown. Stimulation was maximal at $10^{-6} \mathrm{M}$ for $\mathrm{PGE}_{1} ; \mathrm{PGE}_{2}$ and Enisoprost and half maximal at $10^{-7} \mathrm{M}$ (Fig. 2). Figure 3 shows that all three compounds elicited time dependent increases in pepsinogen secretion. In combinations with other secretagogues, we found only additivity between prostaglandins and CCK8 $\left(10^{-4} \mathrm{M}\right)$ or carbachol $\left(10^{-4} \mathrm{M}\right)$ - that is, secretagogues acting through cellular calcium (Table 1).

Table 1 Stored pepsinogen secretion

\begin{tabular}{lll}
\hline Secretagogue & Alone & $+P G E_{1}\left(10^{\circ} M\right)$ \\
\hline Basal & $9 \cdot 4(1 \cdot 3)$ & $26 \cdot 8(3 \cdot 8)$ \\
Carbachol & $34 \cdot 6(6 \cdot 3)$ & $57 \cdot 2(8 \cdot 1)^{*}$ \\
CCK8 & $31 \cdot 3(5 \cdot 7)$ & $53 \cdot 5(6 \cdot 9)^{*}$ \\
dbcAMP & $36 \cdot 7(4 \cdot 7)$ & $34 \cdot 8(4 \cdot 2)$ \\
Forskolin & $31 \cdot 4(3 \cdot 9)$ & $33 \cdot 2(4 \cdot 2)$ \\
\hline
\end{tabular}

Stored pepsinogen secretion was measured after 90 min incubation and expressed as \% of initial pepsinogen content. Data shown are results obtained from four different cell preparations (mean (SD)). ${ }^{*} p<0.05$ compared with secretion by secretagogue alone.
Table 2 Effect of histamine on $P G E_{1}$ stimulated pepsinogen secretion

\begin{tabular}{lll}
\hline [Histamine/ & Alone & $+P G E_{1}\left(10^{\circ} \mathrm{M}\right)$ \\
\hline Basal & $8 \cdot 3(1 \cdot 6)$ & $27 \cdot 9(4 \cdot 5)^{*}$ \\
$10^{\circ} \mathrm{M}$ & $8 \cdot 8(2 \cdot 1)$ & $24 \cdot 8(3 \cdot 8)^{*}$ \\
$10^{\circ} \mathrm{M}$ & $8 \cdot 2(1 \cdot 8)$ & $25 \cdot 7(4 \cdot 2)^{*}$ \\
$10^{\circ} \mathrm{M}$ & $7 \cdot 9(1 \cdot 2)$ & $25 \cdot 6(5 \cdot 3)^{*}$ \\
$10^{\circ} \mathrm{M}$ & $10 \cdot 5(1 \cdot 5)$ & $27 \cdot 3(3 \cdot 7)^{*}$ \\
$10^{\circ} \mathrm{M}$ & $13 \cdot 4(2 \cdot 3)$ & $30 \cdot 4(4 \cdot 3)^{*}$ \\
\hline
\end{tabular}

The incubation medium was assayed for peptic activity after 90 minutes incubation. Pepsinogen secretion was expressed as \% of initial pepsinogen content. Results shown are means derived from three experiments (three different cell preparations) (SD). ${ }^{*} \mathrm{p}<0.005: \dagger \mathrm{p}<0.05$ compared with basal value.

We and others ${ }^{1623}$ have previously reported that histamine has no effect on pepsinogen secretion in vitro, although some have reported stimulation by the histamine analogue betazole hydrochloride in combination with a phosphodiesterase inhibitor such as aminophylline..$^{24} \mathrm{We}$ investigated in this study whether prostaglandins can modify the action of histamine on pepsinogen secretion. Histamine alone caused a slight increase in secretion only at the highest dose tested $\left(10^{-4} \mathrm{M}\right)$, but did not significantly alter prostaglandin stimulated pepsinogen secretion (Table 2).

\section{PEPSINOGEN SYNTHESIS}

In Figure 4 pepsinogen synthesis is shown in time during stimulation of secretion with different secretagogues. As we have previously reported, ${ }^{1-3}$ dbcAMP $\left(10^{-3} \mathrm{M}\right)$ shows the fastest increase in synthesis, already eight-fold higher than basal at 30 minutes, while carbachol induces a similar increase in synthesis but with a delay in response of about $60 \mathrm{~min}$ (Fig. 4b). Forskolin, which is a potent stimulator of dbcAMP production, shows an intermediate response delay (approximately four-fold at 30 minutes). The time course for prostaglandin stimulated synthesis proceeded similar to that of forskolin (Fig. 4a).

We have earlier reported that inhibition of carbachol stimulated secretion by atropine also resulted in a decrease in synthesis. ${ }^{3}$ Atropine did not inhibit basal or dbcAMP stimulated secretion and synthesis. To further clarify the nature of this negative feed back mechanism, we have investigated the effect of pepsin (porcine; Boehringer) itself in the medium, thus mimicking the in vivo situation. As the culture medium has a $\mathrm{pH}>7$, the added pepsin will be inactive. To measure pepsinogen secretion from the cells, medium aliquots were brought to $\mathrm{pH} 9$ for 10 min to irreversibly denature the added pepsin. The concentrations of denatured pepsin used, did not 

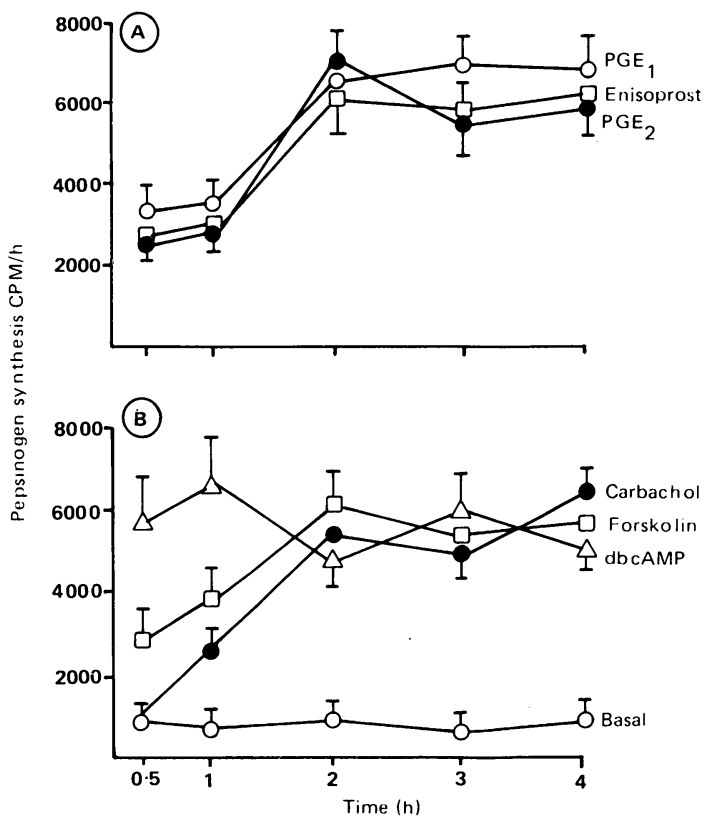

Fig. 4 Time course of pepsinogen synthesis. (A) $P G E_{1}$, $P G E_{2}$, or Enisoprost stimulated $\left(10^{\circ} \mathrm{M}\right)$. (B) Basal and carbachol $\left(10^{\circ} \mathrm{M}\right)$, forskolin $\left(10^{\circ} \mathrm{M}\right)$, or dbcAMP $\left(10^{3} \mathrm{M}\right)$ stimulated. Pepsinogen synthesis at each time point is expressed as CMP/mg total protein per hour and is calculated as the difference between the CPM value at that time point and the CPM value at the previous time point. The 30 min time point was calculated as twice the CPM value at 30 min. Results shown are means $(S D)$ of four experiments (four different cell preparations).

affect measurement of peptic activity (results not shown). Figure 5a shows, that high concentrations of extracellular pepsin, comparable with the gastric juice concentration after stimulation in vivo, inhibits stimulated secretion. At concentrations $>800 \mu \mathrm{g} / \mathrm{ml}$ stimulation of secretion was completely abolished and accompanied by a return to basal synthesis levels (Fig. 5b). In time course experiments, synthesis did not increase when cells were cultured in the presence of both carbachol and pepsin. In contrast, an increase in synthesis with forskolin, dbcAMP or $\mathrm{PGE}_{1}$ was observed during the first two hours of incubation in the same situation (Fig. 6). When pepsin was removed from the medium, cells became responsive to carbachol again.

SECRETION OF NEWLY SYNTHESISED LABELLED PEPSINOGEN

Basal secretion of newly synthesised pepsinogen was $5 \cdot 2(1 \cdot 3) \%$ of total newly synthesised pepsinogen after four hours. Stimulation by the three prostaglandin compounds was again time dependent with
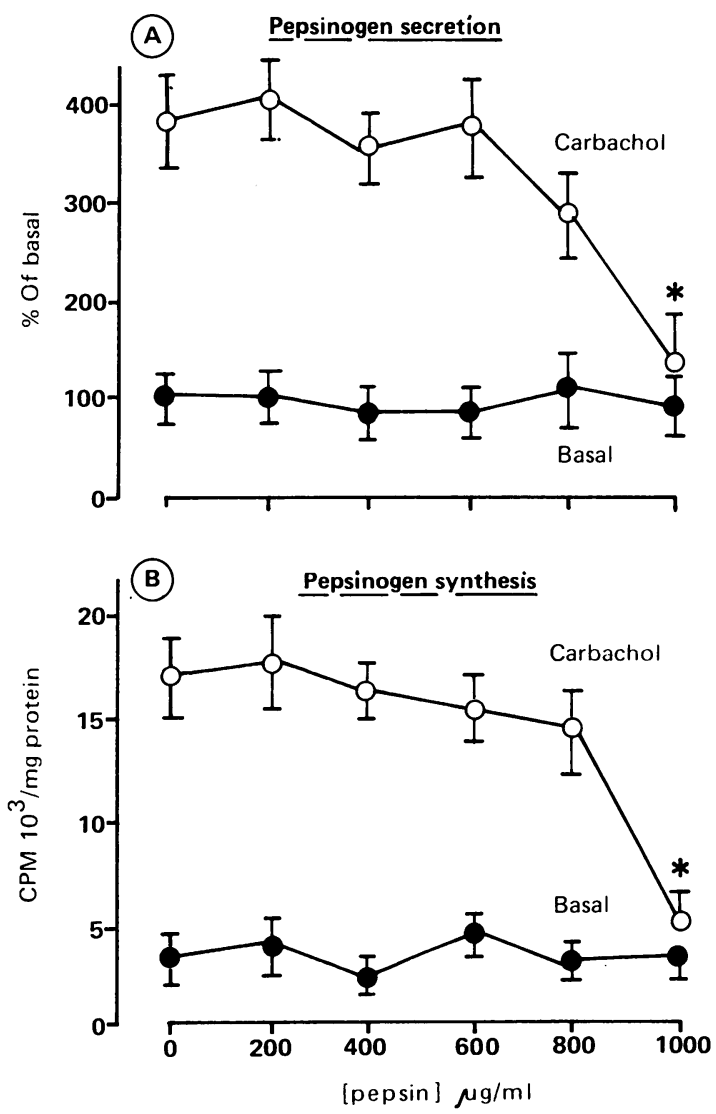

Fig. 5 Dose response effect of extracellular pepsin on pepsinogen secretion $(A)$ and synthesis $(B)$. Pepsinogen secretion was determined after 90 minutes incubation and expressed as \% of basal secretion. Pepsinogen synthesis was determined after 4 hrs culture in ${ }^{14} C$ labelled medium and expressed as $C P M / m g$ total protein. - Basal; $\bigcirc-O$ Carbachol $\left(10^{-4} \mathrm{M}\right)$ stimulated. Data shown are means $(S D)$ derived from four experiments, using four different cell preparations. ${ }^{*} p<0.005$ compared with secretagogue at zero pepsin concentration.

maximal stimulation at $10^{-6} \mathrm{M}$. Labelled pepsinogen was detectable in the medium at the one hour time point for stimulated secretion and two hours for basal secretion (Fig. 7).

\section{EFFECT OF HYDROCHLORIC ACID ON} PEPSINOGEN SECRETION

The effect of $\mathrm{HCl}$ was tested by replacing the insert medium with different concentrations of $\mathrm{HCl}$. Even at the highest concentration tested $(0 \cdot 15 \mathrm{~N})$, we did not observe an increase of pepsinogen secretion (Table 3). No significant changes in the $\mathrm{pH}$ of the basolateral medium in the well ( $\mathrm{pH} 7 \cdot 2)$ were found during these experiments, confirming tight confluent 
Table 3 Effect of acid on pepsinogen secretion and synthesis in chief cell monolayer cultures grown on Millicell culture inserts

\begin{tabular}{|c|c|c|c|c|}
\hline \multirow[b]{2}{*}{ Secretagogue } & \multicolumn{2}{|l|}{ Secretion } & \multicolumn{2}{|l|}{ Synthesis } \\
\hline & Alone & $+\mathrm{HCl}$ & Alone & $+\mathrm{HCl}$ \\
\hline Basal & $8 \cdot 8(1 \cdot 7)$ & $9 \cdot 6(2 \cdot 3)$ & $3050(325)$ & $3170(440)$ \\
\hline $\mathrm{PGE}_{1}$ & $28 \cdot 3(4 \cdot 8)$ & $26 \cdot 7(4 \cdot 3)$ & $18890(1030)$ & $17970(948)$ \\
\hline $\mathrm{PGE}_{2}$ & $29 \cdot 2(4 \cdot 3)$ & $24 \cdot 4(5 \cdot 3)$ & $17970(1120)$ & $18940(1240)$ \\
\hline Enisoprost & $27 \cdot 8(3 \cdot 7)$ & $29 \cdot 3(3 \cdot 8)$ & $20430(1430)$ & $19205(1378)$ \\
\hline Carbachol & $34 \cdot 8(6 \cdot 1)$ & $31 \cdot 5(5 \cdot 6)$ & $16275(770)$ & $16035(830)$ \\
\hline Forskolin & $32 \cdot 3(5 \cdot 4)$ & $29 \cdot 7(4 \cdot 7)$ & $19335(850)$ & $20320(1250)$ \\
\hline
\end{tabular}

Pepsinogen secretion was measured after 90 minutes incubation and expressed as \% of initial pepsinogen content. Pepsinogen synthesis was determined after $4 \mathrm{~h}$ of culture with ${ }^{14} \mathrm{C}$ labelled medium in the well only and is expressed CPM/mg total protein. Secretagogues were also added to the well, while $\mathrm{HCl}$ was added to the insert (final concentration $0 \cdot 15 \mathrm{~N})$. Data shown were obtained from four experiments (mean (SD)), using four different cell preparations.

monolayers. Moreover, we found no effect of hydrochloric acid on pepsinogen secretion stimulated by carbachol, prostaglandins or forskolin in the well medium (Table 3 ). The increased secretion was again concomitant with an increase in synthesis (Table 3 ).

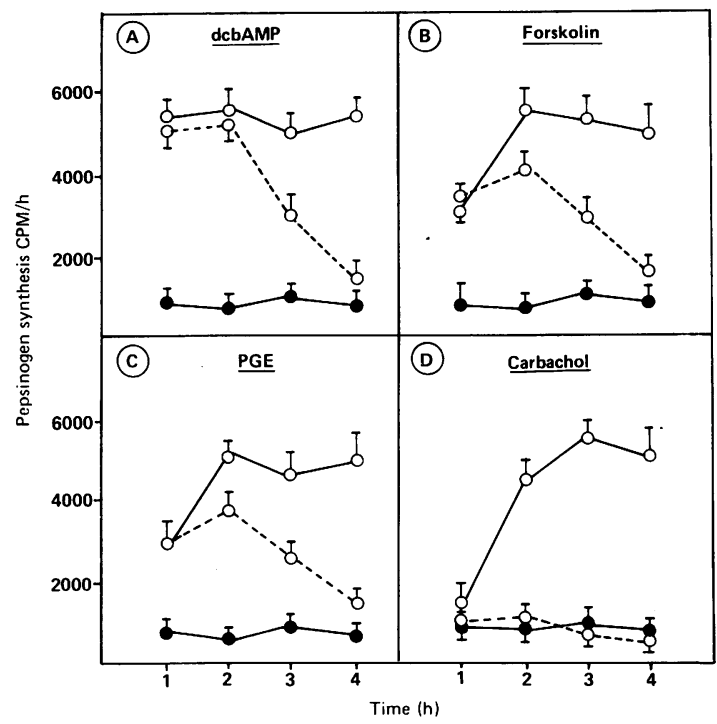

Fig. 6 Time course of pepsinogen synthesis in the presence of dbcAMP $(A)$, forskolin $(B), P G E_{1}(C)$, or carbachol (D) \pm pepsin. Pepsinogen synthesis was determined by culture of cells in ${ }^{14} C$ labelled medium and is expressed as $C P M / m g$ total protein per hour. Pepsin was added to the insert only in a final concentration of $1 \mathrm{mg} / \mathrm{ml}$. Results shown are means $(S D)$, derived from four experiments (four different cell preparations). secretagogue; $\bigcirc----O$ secretagogue+pepsin.
Table 4 Effect of active pepsin on labelled pepsinogen secretion in chief cell monolayers on culture inserts

\begin{tabular}{|c|c|c|}
\hline Secretagogue & Alone & $+\operatorname{Pepsin}(1 \mathrm{mg} / \mathrm{ml})$ \\
\hline Basal & $174(21)$ & $158(18)$ \\
\hline $\mathrm{PGE}_{1}$ & $532(55)$ & $182(25)^{*}$ \\
\hline Carbachol & $746(52)$ & $251(31)^{*}$ \\
\hline Forskolin & $683(63)$ & $212(23)^{*}$ \\
\hline
\end{tabular}

${ }^{14} \mathrm{C}$ labelled pepsinogen secretion was determined after $4 \mathrm{~h}$ culture and expressed as CPM/mg total protein content. Pepsin was added in a $0 \cdot 15 \mathrm{~N} \mathrm{HCl}$ solution (final concentration $\mathrm{mg} / \mathrm{ml}$ ) to the insert only. The $\mathrm{pH}$ of the medium in the well before incubation was 7.4 and after incubation 7·2. Results shown are means (SD) derived from three experiments (three different cell preparations).

${ }^{*} \mathrm{p}<0.005$ as compared with secretion with secretagogue only.

We have also repeated the experiments with pepsin, but now active in acidic apical insert solution $(0 \cdot 1 \mathrm{~N}$ $\mathrm{HCl})$. As in these experiments the secreted endogenous pepsinogen is also converted to pepsin, added exogenous pepsin will interfere in the determination of pepsinogen secretion from the cells. Therefore, cells were cultured in ${ }^{14} \mathrm{C}$ amino acid labelled medium and only labelled pepsinogen secretion was determined. Again an inhibition of stimulated secretion was found (Table 4). Cells were still viable after four hours as tested by trypan blue exclusion. In addition, cells were still responsive to secretagogues after replacement of the acidic pepsin solution with Krebs solution.

\section{Discussion}

Earlier in vivo studies in dog by Johnson ${ }^{25}$ reported stimulation of pepsin secretion by high concentra-

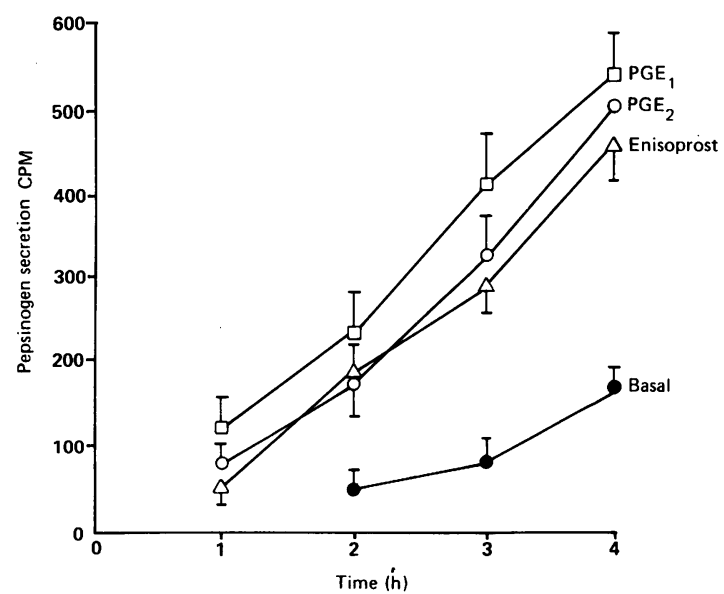

Fig. 7 Time course of labelled pepsinogen secretion in the presence of prostaglandins. Secretion is expressed as CPMI mg total protein content. Results shown are means of four experiments $(S D)$. 
tions of topical hydrochloric acid. It was presumed, that this was caused by ' $\mathrm{H}^{+}$'-receptor mediated local cholinergic reflexes. Later studies in man by Hengels et al, ${ }^{26}$ however, did not confirm these findings. The culture plate insert technique enabled us to study the effect of hydrochloric acid on pepsinogen secretion directly on the chief cell itself. Studies, using chief cell monolayer cultures, mounted in Ussing chambers by Sanders $\mathrm{et}^{\mathrm{al}} \mathrm{l}^{27}$ have already established that the apical surface of the chief cell can resist $\mathrm{H}^{+}$ back-diffusion. In their studies the chief cell monolayer could maintain a $1: 100000 \mathrm{H}^{+}$concentration gradient for more than four hours. No data on pepsinogen secretion were supplied, however. In this study no effect on pepsinogen secretion by $\mathrm{HCl}$ was observed, either on stimulated or on basal secretion. Our finding of a constant remaining $\mathrm{pH}$ in the basolateral medium, while the luminal medium in the insert was replaced by hydrochloric acid and high concentrations of pepsin, confirms the high resistance of the apical surface to acid and active pepsin.

In vivo, natural prostaglandins were found to decrease total pepsin output through reducing gastric juice volume, while pepsin concentration remained constant."12 The synthetic PGE $_{1}$ analogue Enisoprost (Searle) was recently reported to decrease not only total pepsin output, but also the concentration in the gastric juice.$^{28}$ The results of this study clearly show, however, that Enisoprost and the natural prostaglandins have a direct stimulatory effect on the chief cell. Furthermore, this stimulation of pepsinogen secretion seems to be mediated by cAMP as indicated by the additivity with calcium mediated responses only. This situation is thus in strong contrast with the parietal cell, where prostaglandins were found to inhibit histamine stimulated cAMP production. ${ }^{4}$ Changes in the trans-potential differences of the chief cell's apical membrane by histamine and an abolishing of its action by $\mathrm{H}_{2}$ blockers, have been reported ${ }^{29}$ indicating $\mathrm{H}_{2}$ receptors on the apical membrane. Stimulation of pepsinogen secretion by physiological concentrations of histamine alone, however, has not been observed in in vitro studies. In this study, we found an increase in pepsinogen secretion only at very high, nonphysiological doses of histamine, but we did not observe any effect of histamine, either inhibitory or stimulatory, on the actions of prostaglandins.

The results with extracellular pepsin, where an inhibition of stimulated secretion was found, may provide one possible explanation for the observed reduction of total pepsin output in vivo by prostaglandins. The reduction in gastric juice output would result in an increased pepsin concentration. Above a certain threshold concentration (in this study $0.8 \mathrm{mg}$ / $\mathrm{ml}$ ), this will subsequently lead to a reduction of prostaglandin stimulated pepsinogen secretion, resulting in a constant remaining pepsin concentration in the gastric juice itself. Our finding that changes in $\mathrm{pH}$ do not directly affect pepsinogen secretion makes it highly unlikely that a prostaglandin induced increase of the $\mathrm{pH}$ in the gastric gland lumen itself is responsible for the decrease in pepsin release. The diminished acid flow could however prevent a 'washing out' of secreted pepsin into the stomach.

Prostaglandin stimulated pepsinogen secretion was followed by an increase in pepsinogen synthesis. The time course was similar to that of forskolin stimulated synthesis, with a shorter delay in response as compared with carbachol. As in previous studies, ${ }^{1-3}$ dbcAMP stimulated synthesis almost directly, with an increase in synthesis rate already eight-fold higher than basal after 30 minutes. We have earlier proposed ${ }^{3}$ that the differences in response times could result from a direct stimulation of pepsinogen synthesis by agents acting through cAMP as second messenger. Agents, using cellular calcium as mediator were postulated to stimulate pepsinogen synthesis indirectly through a feed back mechanism triggered by increased secretion and emptying of granules. The data of this study support this hypothesis. While extracellular pepsin completely inhibited carbachol stimulated synthesis and secretion, inhibition of synthesis, stimulated by potent stimulators of cAMP synthesis such as forskolin, only became apparent after two hours. This initial increase in pepsinogen synthesis, during simultaneous inhibition of secretion strongly supports a stimulation of synthesis, independently from increased secretion by an increase in cAMP content. Our finding that prostaglandins have a similar effect on pepsinogen synthesis as forskolin that is, initial stimulation of pepsinogen synthesis while secretion is inhibited by pepsin, supports a mediation of their actions by cAMP.

This study was financially supported by a grant from G D Searle.

\section{References}

1 Defize J, Hunt RH. Pepsinogen synthesis and secretion in chief cell monolayers [Abstract]. Gastroenterology 1986; 90: 1391 (A).

2 Defize J, Hunt RH. Control of pepsinogen synthesis and secretion in canine chief cell monolayer cultures [Abstract]. Gut 1986; 27: A 1254.

3 Defize J, Hunt RH. Control of pepsinogen synthesis and secretion in primary monolayer cultures of canine gastric chicf cells. Dig Dis Sci 1988; 33: 1583-91.

4 Ahlquist DA, Duenes JA, Madson TH, Romero JC, Dozois RR, Malagelada JR. Prostaglandin generation 
from gastro duodenal mucosa: regional and species differences. Prostaglandins 1982; 24: 115-25.

5 Bennet AJ, Murray JC, Willie JG. Occurrence of PGE in the human stomach and a study of its effects on human isolated gastric muscle. $\mathrm{Br} J$ Pharmacol Chemother 1968; 32: 339-49.

6 Mangeat P, Gespasch C, Maschia-Mouren G, Roselin G. Differential effects of histamine, vaso active peptide, $\mathrm{PGE}_{2}$ and somatostatin on cyclic AMP dependent protcin kinase activation in gastric glands isolated from the guinea pig fundus and antrum. Regul Pept 1982; 3: $155-68$.

7 Main IHM, Ehittle BJR. The effects of E and A prostaglandins on gastric mucosal blood flow and acid secretion in the rat. Br J Pharmacol 1973; 49: 428-36.

8 Nezamis JE, Robert A, Stowe DF. Inhibition by prostaglandin $E_{1}$ on canine gastric acid secretion and gastric mucosal blood flow. Am J Dig Dis 1972; 17: 52732.

9 Soll AH. Specific inhibition by prostaglandin $E_{1}$ and $I_{2}$ of histamine stimulated $\left[{ }^{14} \mathrm{C}\right] \mathrm{AP}$ accumulation and cAMP generation by isolated parietal cells. J Clin Invest 1980; 65: 1222-9.

10 Wollin H, Soll AH, Samloff IM. Actions of histamine, secretin and $\mathrm{PGE}_{2}$ on cyclic $\mathrm{AMP}$ production by isolated canine fundic mucosal cells. Am J Physiol 1979; 237: E437-43.

11 Robert A. Effect of prostaglandin on the stomach and the intestine. Prostaglandins 1974; 6: 523-32.

12 Robert A. Prostaglandin and the gastrointestinal tract. In: Johnson LP, ed. Physiology of the gastrointestinal tract. New York: Raven Press, 1981: 1407-34.

13 Berger S, Raufman JP. Prostaglandin induced pepsinogen secretion from dispersed gastric glands from guinea pig stomach. Am J Physiol 1985; 249: G592-8.

14 Defize J, Arwert F, Kortbeek H, Frants RR, Meuwissen SGM, Eriksson AW. Pepsinogen synthesis and secretion in monolayer culture of human and rabbit gastric mucosal cells. Virchows Arch B 1985; 49: 225-30.

15 Beglindh T, Obrink KJ. A method for preparing isolated glands from the rabbit gastric mucosa. Acta Physiol Scand 1976; 96: 150-9.

16 Defize J, Pals G, Westerveld BD, Frants RR, Meuwissen SGM, Eriksson AW. Pepsinogen synthesis and secretion in isolated gastric glands. J Clin Pathol 1984; 37: $531-6$.

17 Fryklund J, Wallmark B, Larsson H, Helander HF.
Effect of omeprazole on gastric secretion in $\mathrm{H}+\mathrm{K}+-$ ATPase and in pepsinogen-rich cell fractions from rabbit gastric mucosa. Biochem Pharmacol 1984; 33: 273-80.

18 Meuwissen SGM, Mullink H, Bosma A, et al. Immunocytochemical localization of pepsinogen $A$ and $C$ in the human stomach. Prog Clin Biol Res 1985; 173: 185-98.

19 Defize J, Pals G, Frants RR, et al. The influence of omeprazole on the synthesis and secretion of pepsinogen in isolated gastric glands. Biochem Pharmacol 1985; 34: 3693-9.

20 Bradford MM. A rapid and sensitive method for the quantitation of microgram quantities of protein, utilizing the principle of protein-dye binding. Anal Biochem 1976; 72: 248-54.

21 Berstad A. A modified hemoglobin substrate method for the estimation of pepsin in gastric juice. Scand $J$ Gastroenterol 1970; 5: 343-8.

22 Sanders MJ, Amirian DA, Ayalon A, Soll AH. Regulation of pepsinogen release from canine chief cells in primary monolayer culture. Am J Physiol 1983; 245: G641-6.

23 Koclz HR, Hersey SJ, Sachs G, Chew GS. Cholinergic and beta-adrenergic pepsinogen release by isolated rabbit glands. Am J Physiol 1982; 243: G218-25.

24 Ito M, Noguchi Y, Yokochi K, Kishimoto T, Tomomatsu T, Katsumi K, Takeuchi T. Effects of betazole hydrochloride and cyclic AMP on the pepsinogen secretion by rabbit gastric mucosa in organ culture. Digestion 1982; 23: 169-73.

25 Johnson LR. Effect of gastric mucosal acidification on the actions of pepsigogues. Am J Physiol 1973; 225: 1411-5.

26 Hengels KJ, Wagener R, Strohmeyer G, Samloff IM. Effect of topical acid on gastric pepsin output in man [Abstract]. Gastroenterology 1986; 90: 1458 (A).

27 Sanders MJ, Ayalon A, Roll M, Soll AH. The apical surface of canine chicf cell monolayers resists $\mathrm{H}^{+}$backdiffusion. Nature 1985; 313: 52-4.

28 Howden CW, Burget DW, van Eeden A, Hunt RH. Enisporost: marked inhibition of histamine stimulated acid and pepsin secretion in man [Abstract]. Gastroenterology 1986; 90: 1466 (A).

29 Ayalon AM, Sanders J, Thomas LP, Amirian DA, Soll AH. Electrical effects of histamine on monolayers formed in culture from enriched canine gastric chicf cells. Proc Natl Acad Sci USA 1982; 79: 7009-13. 